Podziękowania. Dziękuję uczestnikom dziewiątego Studenckiego Obozu Botanicznego, zorganizowanego w Puszczy Augustowskiej w dniach 10-16 lipca 2016 r. w Gibach przez stowarzyszenie Centrum Ochrony Mokradeł, za udział w niniejszych badaniach.

Summary. Vascular plants of the Tobolinka Nature Reserve in the Augustów Forest. A detailed study of vascular plants in the Tobolinka Nature Reserve (Augustów Forest, NE Poland) was carried out in July 2016 and February 2020. The reserve covers a very small area, and the diversity of its plant communities is very low due to the high acidity of its habitats (extremely poor fen surrounding a small polyhumic lake; wet and mesic pine forest). Only 48 species were recorded, including five species red-listed nationally (e.g. Goodyera repens, Scheuchzeria palustris).

\title{
LITERATURA
}

Kaźmierczakowa R., Bloch-OrŁowska J., Celka Z., Cwener A., Dajdok Z., Michalska-Hejduk D. PAWLIKOWSKI P., SZCZEŚSIAK E. \& ZIARNEK K. 2016. Polska czerwona lista paprotników i roślin kwiatowych. s. 44. Instytut Ochrony Przyrody Polskiej Akademii Nauk, Kraków.

KondRACKI J. 2002. Geografia regionalna Polski. s. 440. Wydawnictwo Naukowe PWN, Warszawa.

Mirek Z., PięKoś-Mirkowa H., ZająC A. \& ZająC M. 2002. Flowering plants and pteridophytes of Poland. A checklist. - W: Z. MireK (red.), Biodiversity of Poland. 1, s. 1-442. W. Szafer Institute of Botany, Polish Academy of Sciences, Kraków.

RozPorZąDZENIE Ministra Środowiska z dnia 9 października 2014 r. w sprawie ochrony gatunkowej roślin (Dz. U. z 2014 r., poz. 1409)

SoKoŁowski A. W. 2006. Przyroda województwa podlaskiego i jej ochrona. s. 336. Łomżyńskie Towarzystwo Naukowe im. Wagów, Łomża.

SokoŁowski A. W. 2010. Puszcza Augustowska. s. 292. Centrum Informacyjne Lasów Państwowych, Warszawa.

ZAJAc A. 1978. Atlas of distribution of vascular plants in Poland (ATPOL). - Taxon 27(5-6): 481-484.

Pawee Pawlikowski, Zakład Ekologii Roślin i Ochrony Środowiska, Instytut Botaniki, Wydziat Biologii, Centrum Nauk Biologiczno-Chemicznych, Uniwersytet Warszawski, ul. Żwirki $i$ Wigury 101,02-096 Warszawa,Polska; e-mail p.pawlikowski@uw.edu.pl

Wptynęto: 25.02.2020 r.; przyjęto do druku: 17.12.2020 r.

DOI: https://doi.org/10.35535/ffgp-2020-0038

\section{Nowe stanowisko Botrychium lunaria (Ophioglossaceae) w Krakowie na tle danych historycznych}

Botrychium lunaria (L.) Sw., podejźrzon księżycowy, jest gatunkiem o zasięgu cyrkumborealnym (ZAJĄC \& ZAJĄC 2009), najczęściej spotykanym przedstawicielem rodzaju Botrychium Sw. (Ophioglossaceae) w Polsce. W związku z obserwowanym spadkiem liczby stanowisk w ostatnich dziesięcioleciach gatunek zaliczony został do narażonych we florze Polski (ZARZYCKI i in. 2002; ZARZYCKI \& SZELĄG 2006; KAŹMIERCZAKOWA i in. 2016), 
a od 2004 r. podlega ochronie ścisłej (ROZPORZĄDZENIE 2004), obecnie jako gatunek wymagający ochrony czynnej (RozPORZĄDZENIE 2014). W okolicach Krakowa należy do grupy gatunków rzadkich i ginących, a w samym Krakowie uznany został w 1998 r. za wymarły (ZAJĄC \& ZAJĄC 1998). W późniejszych latach gatunek stwierdzono w granicach miasta tylko raz, w Tyńcu w 2005 r. (ZAJĄC i in. 2006; baza danych ATPOL).

Jest to paproć grubozarodniowa, o pionowym, wieloletnim kłączu, z którego corocznie wyrasta jeden żółtozielony liść (osiągający od 5 do $30 \mathrm{~cm}$ wysokości), z blaszką podzieloną na część płonną, pojedynczo pierzastą (o odcinkach półksiężycowatych do klinowatych) oraz zwykle długoogonkową część zarodnionośną, 1-3-krotnie pierzastą (RACIBORSKI 1919; SzAFER i in. 1986; WÓJCIAK 2007), z zarodnikami dojrzewającymi od czerwca do lipca (Dostál 1984), a według WóJCiAK (2007) oraz TLAŁKI i RostAŃSKIEGO (2012) od maja do sierpnia. U przedstawicieli różnych gatunków Botrychium potwierdzono obecność mikoryzy arbuskularnej (WINTHER \& FRIEDMAN 2007). Botrychium lunaria jest gatunkiem światłolubnym, występującym na suchych łąkach i pastwiskach, w murawach oraz przy ścieżkach w prześwietlonych lasach (DosTáL 1984), uznanym za charakterystyczny dla muraw bliźniczkowych z rzędu Nardetalia (MATuszKiewicz 2001).

Pomimo długiej i bogatej historii badań botanicznych oraz dostępności odpowiednich siedlisk, Botrychium lunaria podano dotychczas z obszaru Krakowa (w aktualnych granicach) tylko z 5 jednostek kartogramu w sieci ATPOL o boku $2 \mathrm{~km}$ (ZAJĄC i in. 2006). Wszystkie stanowiska pochodzące z okresu do 1944 r., oparte na danych opublikowanych przez RACIBORSKIEGO (1884) - DF: 6931, 6932, 6934 (ZAJĄC \& ZAJĄC 1998; ZAJACC i in. 2006; baza danych ATPOL), uznane zostały za wymarłe (ZAJĄC \& ZAJĄC 1998). Według ZAJAC $\mathrm{i}$ in. (2006) podano lub potwierdzono po jednym stanowisku w przedziałach czasowych: 1945-1992 (DF6814) i 1993-2006 (DF7804).

W krakowskich zielnikach Instytutu Botaniki Uniwersytetu Jagiellońskiego (KRA) i Instytutu Botaniki im. W. Szafera Polskiej Akademii Nauk (KRAM) znajduje się 10 arkuszy zielnikowych z okazami Botrychium lunaria z omawianego obszaru. Dotyczą one okazów z następujących stanowisk:

- pod Kopcem Kościuszki na Sikorniku na skale, 15.06.1866, leg. W. Jabłoński (KRAM 398601);

- Sikornik: 1875, leg. W. Kulczyński (KRAM 398555, 398619); 07.1875, leg. SZ [S. Zaręczny] (KRA 204710); (z dopiskiem u góry etykiety czarnym atramentem: „Kłosy 1873”), 06.1880, leg. ? [M. Raciborski] (KRA 204705); 9.08.1884, leg. M. Raciborski (KRA 86792);

- Grota Twardowskiego, Krzemiona (z dopiskiem u góry etykiety czarnym atramentem: „Kłosy 1875”), 05.1880, leg. ? [M. Raciborski], informacja na kartce dopiętej do arkusza: „Z zieln. M. Raciborskiego" (KRA 204668);

- Skały Twardowskiego, suche wzgórza, 24.09.1909, leg. A. Żmuda (KRAM 46270);

- Tyniec, wzgórze wapienne koło szosy - w murawie, 13.06.1967, leg. H. Trzcińska-Tacik (KRAM 390022); Tyniec - wzgórze koło szosy, 13.06.1967, leg. ? (KRA 62550).

Pierwsze stanowiska Botrychium lunaria z obszaru położonego w dzisiejszych granicach Krakowa opublikował RACIBORSKI (1884), wymieniając w oparciu o własne „spostrzeżenia” następujące lokalizacje: „Sikornik, Dębniki naprzeciw kopca Kościuszki, Krzemionki za kościołem na Podgórzu". Jednak już znacznie wcześniej, bo w 1866 r., gatunek ten zebrany został przez W. Jabłońskiego „pod Kopcem Kościuszki na Sikorniku na skale” (KRAM 398601). Z Sikornika pochodzi większość arkuszy zielnikowych dotyczących 
Krakowa - B. lunaria zbierano tam jeszcze kilkukrotnie: w 1875 r. W. Kulczyński (KRAM 398555, 398619) i S. Zaręczny (KRA 204710) oraz w 1880 r. (KRA 204705) i w 1884 r. (KRA 86792) M. Raciborski. Do okazów zebranych z Sikornika „pod Krakowem” przez W. Kulczyńskiego odnosił się ZAPAŁowicz (1906). Nie zachował się żaden okaz z Krzemionek Podgórskich, natomiast stanowisko „Dębniki naprzeciw Kopca Kościuszki” podane przez RACIBORSKIEGO (1884) wiąże się prawdopodobnie z materiałem zielnikowym zebranym w 1880 r. przy Grocie Twardowskiego (KRA 204668). W górnej części oryginalnych etykiet zielnikowych dwóch arkuszy z zielnika M. Raciborskiego z 1880 r. znajdują się dopiski, wykonane innym kolorem atramentu. W przypadku zbioru z Sikornika dopisano: „Kłosy 1873”, zaś na etykiecie okazów z okolicy Groty Twardowskiego znajduje się informacja: „Kłosy 1875”. Oznacza to, że na tych dwóch stanowiskach gatunek obserwowany był już wcześniej. Sam Raciborski pisał, że wycieczki podejmował od $1878 \mathrm{r}$. (RACIBORSKI 1884), więc prawdopodobnie otrzymał informacje o występowaniu B. lunaria na tych stanowiskach od starszych od niego badaczy flory okolic Krakowa (w 1873 r. miał 10 lat). W gronie osób, które udostępniały mu niepublikowane dane florystyczne (które np. znalazły się w jego pracy dotyczącej zmian we florze okolic Krakowa; RACIBORSKI 1884) był m.in. geolog, dr Stanisław Zaręczny, który odegrał ważną rolę w życiu Raciborskiego (PiekietKo-Zemanek 1986); od 1876 r. nauczyciel Wyższej Szkoły Realnej w Krakowie (AleXANDRowicz 2014), do której Raciborski uczęszczał od 1874 do 1880 r. (PIEKIEŁKoZEMANEK 1986), a w latach późniejszych jego przyjaciel (KuLCZYŃski 1977). Do niego należy podpis „SZ” umieszczony na etykiecie arkusza zielnikowego z B. lunaria z Sikornika z 1875 r. (KRA 204710).

Z XX w. pochodzą tylko trzy notowania gatunku. W 1909 r. Botrychium lunaria zebrał A. Żmuda (KRAM 46270) na „suchych wzgórzach” na Skałach Twardowskiego (ŻMUDA 1920). Następne stanowisko potwierdzone okazami zielnikowymi (KRAM 390022, KRA 62550; zebranymi w tym samym dniu przez $\mathrm{H}$. Trzcińską-Tacik i drugą osobę, której nazwisko jest nieczytelne) znalezione zostało dopiero w 1967 r. na wapiennym wzgórzu w Tyńcu. W 1988 r. gatunek został zanotowany przez H. Trzcińską-Tacik (dane z bazy ATPOL) na wapienniku w Mydlnikach (DF6814; ZAJąC i in. 2006). Na początku XXI w. gatunek został ponownie znaleziony w Tyńcu (dane z bazy ATPOL: „Tyniec, kamieniołom” oraz „Kraków - Tyniec”) przez M. Waydę (DF7804; ZAJąC i in. 2006).

Z informacji na arkuszach zielnikowych i pochodzących z literatury wynika, że w obrębie Krakowa gatunek notowany był głównie w murawach porastających skały wapienne, budujące zręby Krzemionek Zakrzowskich, Krzemionek Podgórskich, Sikornika w Pasmie Sowińca oraz Tyńca.

Nowe stanowisko Botrychium lunaria stwierdzone zostało w południowo-zachodniej części Krakowa w rejonie Zakrzówka (dzielnica Dębniki), w obrębie łąk zlokalizowanych pomiędzy ulicami Łojasiewicza i Norymberską. Kilka osobników B. lunaria obserwowano po raz pierwszy na omawianym stanowisku 28 maja 2012 r. Rosły one wzdłuż ścieżki prowadzącej przez łąkę w kierunku ulicy Norymberskiej. W kolejnym roku, 25 maja, znalezione zostało nieopodal (w odległości kilkunastu metrów) liczniejsze skupisko tej paproci, obejmujące 32 osobniki (Ryc. 1). Nie udało się natomiast odnaleźć paproci w miejscu obserwacji z 2012 r. Stanowisko to znajduje się w kwadracie ATPOL (o boku 2 km) DF6942 


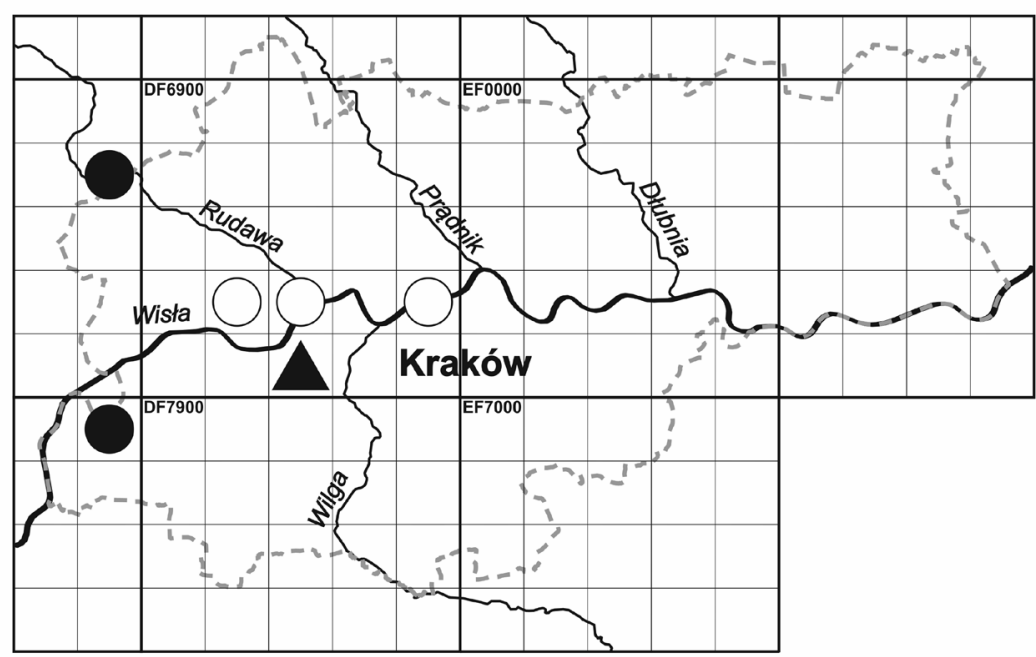

Ryc. 1. Rozmieszczenie Botrychium lunaria w Krakowie. Stanowiska znane z materiałów zielnikowych i literatury: o - z XIX w., $\bullet-$ z XX w. i na początku XXI w.; $\boldsymbol{\Delta}$ - nowe stanowisko

Fig. 1. Distribution of Botrychium lunaria in Cracow. Localities known from herbaria and literature: $\circ-$ in the 19th century, $\bullet$ - in the 20 th and early 21 st centuries; $\boldsymbol{\Delta}$ - new locality

(Ryc. 1). Pomimo prowadzonych poszukiwań w maju i czerwcu w latach 2014, 2016 i 2020 , B. lunaria nie stwierdzono ponownie.

Paproć występowała w ubogim płacie łąki świeżej ze związku Arrhenatherion (Zdj. 1), nawiązującym do muraw bliźniczkowych poprzez udział gatunków charakterystycznych dla klasy Nardo-Callunetea - poza Botrychium lunaria są to: Luzula campestris, Potentilla erecta oraz Viola canina; w sąsiedztwie występuje także w niewielkiej ilości Nardus stricta. Płat z Botrychium lunaria zlokalizowany jest na obszarze zajętym przez gleby murszaste (SkiBA i in. 2008), na podłożu kwaśnym (pH 5,1), z dużą zawartością piasku. Nomenklaturę syntaksonomiczną podano za MATUSZKIEWICZEM (2001), a nazwy wymienionych w pracy gatunków roślin za MiRKIEM i in. (2002).

Zdj. 1. Współrzędne geograficzne: $50^{\circ} 1^{\prime} 58,39^{\prime \prime} \mathrm{N}, 1^{\circ} 54^{\prime} 14,29^{\prime \prime} \mathrm{E}$; data: 25.05 .2013 , pow. $50 \mathrm{~m}^{2}$. Zwarcie w warstwach: $\mathrm{b}-10 \%, \mathrm{c}-95 \%, \mathrm{~d}-1 \%$. Wysokość runi: maksymalna $-50 \mathrm{~cm}$, średnia $-20 \mathrm{~cm}$.

b: Padus serotina 2, Quercus robur 1; c: Achillea millefolium 2, Agrimonia eupatoria + , Angelica sylvestris + , Anthoxanthum odoratum 1, Botrychium lunaria + , Carex hirta 1, Centaurea jacea 1, Cerastium arvense 1, Crepis biennis + , Dactylis glomerata + , Equisetum arvense + , Festuca rubra 2 , Fragaria viridis 1, Galium mollugo +, G. verum 2, Holcus lanatus + , Lathyrus pratensis + , Leontodon hispidus + , Luzula campestris 2, Lysimachia vulgaris 2 , Ononis arvensis + , Plantago lanceolata + , Poa angustifolia 3, Potentilla anserina 1, P. erecta 1 , Quercus robur + , Ranunculus acer,$+ R$. repens + , Rhinanthus $\mathrm{sp.}+$, Rumex thyrsiflorus + , Taraxacum officinale + , Veronica chamaedrys 2, Vicia sp. + , Viola canina 1.

Zagrożenia dla gatunku na opisanym stanowisku wynikały do niedawna głównie z braku użytkowania łąk i można je było określić jako odwracalne (brak koszenia lub wypasania powodował zwiększanie warstwy wojłoku, zacienienie i zwiększoną konkurencję ze strony wkraczających gatunków inwazyjnych, takich jak Solidago gigantea i Padus serotina) oraz bezpośredniego zagrożenia w wyniku wydeptywania osobników występujących wzdłuż 
ścieżek. Sytuacja zmieniła się w ostatnich latach, gdyż łąki były koszone, a rozrastające się licznie młode osobniki Padus serotina zostały wycięte, jednakże równocześnie wzrosła intensywność wydeptywania części łąki, na której obserwowany był podejźrzon księżycowy (w związku z wykaszaniem runi ruch pieszych nie ogranicza się obecnie do istniejących od dawna ścieżek, lecz wydeptywane są kolejne fragmenty łąki). Zagrożeniem nieodwracalnym może okazać się planowana budowa Trasy Pychowickiej (część III obwodnicy Krakowa), w bezpośrednim sąsiedztwie której znajdzie się opisane stanowisko. Dla zachowania siedliska Botrychium lunaria będzie miał znaczenie stopień ingerencji w czasie budowy drogi oraz sposób użytkowania tego obszaru po jej zakończeniu. Według miejscowego planu zagospodarowania (UCHWAŁA 2018) stanowisko znajduje się w obrębie dwóch pasów: przeznaczonego pod skwery i zieleńce terenu zieleni uporządkowanej oraz zieleni izolacyjnej.

Odnotowanie stanowisk rzadkich gatunków na obszarze Krakowa (podobnie jak i innych miast) ma szczególne znaczenie ze względu na szybkie tempo zmian w środowisku przyrodniczym aglomeracji miejskiej, skutkujących zanikiem zarówno cennych gatunków roślin, jak i całych siedlisk. Żadne spośród znanych w XIX w. stanowisk Botrychium lunaria z Krzemionek Zakrzowskich, Sikornika, czy Krzemionek Podgórskich, nie zostało potwierdzone. Może to być spowodowane wyginięciem gatunku na wspomnianych obszarach w wyniku znacznego przekształcenia siedlisk na skutek braku ich użytkowania, w tym zarastania przez krzewy i drzewa (także celowego zalesienia), lub nadmiernej eksploatacji (jak np. intensywne wydeptywanie, rozjeżdżanie, czy w ekstremalnych przypadkach eksploatacja wapieni lub zabudowa terenu). Z drugiej strony brak nowych danych może być także skutkiem nałożenia się kilku czynników: braku celowych poszukiwań gatunku, trudności w jego odnajdywaniu ze względu na niepozorny wygląd, niewielkie rozmiary i specyficzny cykl życiowy (np. JoHnSON-GROH \& LEE 2002), jak również ogólnym zmniejszeniem zainteresowania badaniami florystycznymi. Charakterystyczne dla przedstawicieli rodzaju Botrychium jest występowanie okresowych przerw w corocznym, cyklicznym rozwoju liści, przy czym przerwy te mogą trwać nawet kilka lat (JOHNSON-GROH \& LEE 2002). Jako powód nieobecności liści podawane są niekorzystne warunki pogodowe, i tak np. u B. lunaria liście często pojawiają się obficie w mokrych latach, zaś w przypadku wystąpienia wiosennej suszy części nadziemne mogą się w ogóle nie wykształcić (Dostál 1984).

Opisane nowe stanowisko położone jest w pobliżu Krzemionek Zakrzowskich, gdzie Botrychium lunaria stwierdził w maju 1880 r. M. Raciborski w otoczeniu Groty Twardowskiego oraz pod koniec września 1909 r. A. Żmuda na Skałach Twardowskiego (stanowiska zlokalizowane w sąsiednich jednostkach ATPOL o boku $2 \mathrm{~km}$ ). Od końca XIX w. obszary te i sposoby ich użytkowania zmieniły się znacząco, co wpłynęło na rozmieszczenie całych zbiorowisk, jak i poszczególnych gatunków roślin. Również obecnie zmiany zachodzące na tym terenie (postępująca zabudowa, odwodnienia, zaprzestanie systematycznego użytkowania łąk) znacząco oddziałują na szatę roślinną. Ponowne stwierdzenie B. lunaria w rejonie Zakrzówka po przeszło stu latach, potwierdza wysokie walory przyrodnicze tego terenu, umożliwiającego trwanie populacji rzadkich gatunków roślin pomimo znaczących przemian jakie zaszły w tej części Krakowa, a obejmujących m.in. prowadzoną od stuleci eksploatację wapieni (SERMET \& ROLKA 2013). Obszar ten jest miejscem występowania rzadkich, 
chronionych oraz zagrożonych gatunków roślin naczyniowych (DuBIEL i in. 2011), w tym gatunków posiadających tutaj jedne z ostatnich już stanowisk w granicach Krakowa, jak np. Pulsatilla pratensis, ,pałubka” Stanisława Wyspiańskiego rysowana z natury 23 maja 1896 r. przy grocie Twardowskiego (PUCHALSKI 1959: karta 4), stwierdzona ponownie po wielu latach przez KRZEPTOwsKą i in. (2006) w murawie na Skałach Twardowskiego.

Odkrycie gatunku na tym terenie jest tym ważniejsze, że od lat 70. i 80. XX w. kiedy okazy Botrychium lunaria były zbierane w Tyńcu i notowane w Mydlnikach przez H. Trzcińską-Tacik, gatunek zanotowano w Krakowie tylko raz, w 2005 r. (M. Wayda), potwierdzając tym samym jego występowanie w Tyńcu (ZAJĄc i in. 2006; baza danych ATPOL). W związku ze stwierdzeniem B. lunaria na obszarze łąk sąsiadujących z obszarami, na których gatunek był notowany w przeszłości i niespotykany przez ponad sto lat, można żywić nadzieję, że uda się odnaleźć kolejne jeszcze stanowiska w Krakowie.

Podziękowania. Dziękujemy Panu Profesorowi Adamowi Zającowi za udostępnienie wykazu stanowisk Botrychium lunaria zgromadzonych w bazie ATPOL oraz Kierownikom i Pracownikom Zielników Instytutu Botaniki UJ oraz Instytutu Botaniki im. W. Szafera PAN za możliwość skorzystania ze zbiorów. Dr Agnieszce Nikel dziękujemy za uwagi do tekstu pracy.

Summary. New locality of Botrychium lunaria (Ophioglossaceae) in Kraków (S Poland) and its historical background. Botrychium lunaria was classified as vulnerable in the flora of Poland (ZARZYCKI et al. 2002; ZARZYCKI \& SZELAG 2006; KAŹMIERCZAKOWA et al. 2016) due to the decrease in its number of localities in recent decades. In Cracow it was declared extinct in 1998 (ZAJAC \& ZAJAC 1998), and since then was noted only once in 2005 (ZAJAC et al. 2006; data from the ATPOL database). The first localities of Botrychium lunaria in Cracow were given in the second half of the 19th century, when it was recorded several times: by W. Jabłoński in 1866, W. Kulczyński and S. Zaręczny in 1875, and M. Raciborski in 1880 and 1884 . However, in the 20th century it was found only three times: by A. Żmuda in 1909 and by $\mathrm{H}$. Trzcińska-Tacik in 1967 and 1988. At the beginning of the 21st century, B. lunaria was noted once, by M. Wayda in 2005. According to information available in herbarium sheets and literature, within Cracow it was recorded mainly in calcareous grassland in Krzemionki Zakrzowskie, Krzemionki Podgórskie, Sikornik in the Sowiniec Range, and Tyniec.

On May 28, 2012, a new locality of Botrychium lunaria (several individuals) was found along a path in a meadow in the Zakrzówek area (Dębniki district), between Łojasiewicza Street and Norymberska Street in the south-western part of Cracow. In the following year, on May 25, a larger cluster of this fern - 32 individuals, all with developed fertile sporophores (Fig. 1) - was found about $15 \mathrm{~m}$ away from the locality found in 2012. However, the fern could not be found at that first site. The described stand is located in ATPOL square DF6942 (2×2 km square) (Fig. 1). Searches in May and June in 2014, 2016 and 2020 did not reconfirm those records.

Until 2013, threats to Botrychium lunaria at the described site resulted mainly from the lack of use of meadows, invasion by expansive species (Solidago gigantea, Padus serotina) and trampling of plants growing along paths. In recent years the meadows were mowed and Padus serotina plants were cut down, but at the same time the intensity of trampling of the part of the meadow with B. lunaria increased (people use the old paths but also trample new paths, so more parts of the meadow are destroyed). The planned Trasa Pychowicka (part of Cracow's third beltway) in the immediate vicinity of the meadow may pose an irreversible threat to that habitat.

Recording new sites of rare species in the Cracow area is especially important, in view of rapid changes in the natural environment of the urban agglomeration, resulting in the disappearance of particular plant species and entire habitats. The new locality follows the historical ones found at Krzemionki Zakrzowskie in May 1880 by M. Raciborski and at the end of September 1909 by A. Żmuda. Rediscovery of Botrychium lunaria in the Zakrzówek area after more than a hundred years confirms the high natural values of this area, allowing rare plant species to survive despite significant changes in use and vegetation. 


\section{LITERATURA}

AleXANDROwicz S. W. 2014. Stanisław Zaręczny (1848-1909) geolog - wybitny znawca Ziemi Krakowskiej. Komisja Historii Nauki PAU, Monografie 21, s. 131. Polska Akademia Umiejętności, Kraków.

DostáL J. 1984. Botrychium. - W: K. U. Kramer (red.), Gustav Hegi Illustrierte Flora von Mitteleuropa. Band I. Pteridophyta, Teil 1, s. 87-95. Wyd. 3. Verlag Paul Parey, Berlin - Hamburg.

Dubiel E., Nobis A. \& Nobis M. 2011. Flora roślin naczyniowych i zbiorowiska roślinne Zakrzówka (Kraków). - Fragmenta Floristica et Geobotanica Polonica 18(1): 47-81.

Johnson-Groh C. L. \& LeE J. M. 2002. Phenology and demography of two species of Botrychium (Ophioglossaceae). - American Journal of Botany 89(10): 1624-1633.

Kaźmierczakowa R., Bloch-OrŁowska J., Celka Z., Cwener A., Dajdok Z., Michalska-Hejduk D., PAwlikowski P., SzCZĘ́ŚniaK E. \& ZiARneK K. 2016. Polska czerwona lista paprotników i roślin kwiatowych. s. 44. Instytut Ochrony Przyrody Polskiej Akademii Nauk, Kraków.

Krzeptowska I., Moszkowicz Ł. \& ZabŁocka D. 2006. Populacja sasanki łąkowej Pulsatilla pratensis (L.) Mill. na Skałach Twardowskiego w Krakowie. - Chrońmy Przyrodę Ojczystą 62(2): 28-40.

KULCZYŃsKi S. 1977. Korespondencja między Marianem Raciborskim a Władysławem Kulczyńskim z lat 1895-1917. - Studia i Materiały z Dziejów Nauki Polskiej, Seria B, Historia Nauk Biologicznych i Medycznych 27: 19-47.

Matuszkiewicz W. 2001. Przewodnik do oznaczania zbiorowisk roślinnych Polski. s. 537. Wydawnictwo Naukowe PWN, Warszawa.

Mirek Z., PięKoś-Mirkowa H., ZająC A. \& ZająC M. 2002. Flowering plants and pteridophytes of Poland. A checklist. - W: Z. MireK (red.), Biodiversity of Poland. 1, s. 442. W. Szafer Institute of Botany, Polish Academy of Sciences, Kraków.

PiekieŁKo-ZemaneK A. 1986. Kalendarium życia Mariana Raciborskiego. - W: J. KoRnAś (red.), Marian Raciborski. Studia nad życiem i działalnością naukową. Zeszyty Naukowe Uniwersytetu Jagiellońskiego - Varia 110, s. 9-43. Państwowe Wydawnictwo Naukowe, Warszawa - Kraków.

PięKoŚ-Mirkowa H. \& MireK Z. 2018. Rośliny chronione. s. 464. MULTICO Oficyna Wydawnicza, Warszawa.

Puchalski G. (oprac.) 1959. Stanisław Wyspiański. Twórczość plastyczna. Seria I. Zielnik. Wydawnictwo Literackie, Kraków.

RACIBORSKI M. 1884. Zmiany zaszłe we florze okolic Krakowa w ciągu ostatnich dwudziestu pięciu lat pod względem roślin dziko rosnących. - Sprawozdanie Komisyi Fizyjograficznej 18: 99-126.

Raciborski M. 1919. Botrychium Sw. - W: M. Raciborski \& W. Szafer (red.), Flora polska. Rośliny naczyniowe Polski i ziem ościennych 1, s. 5-8. Nakładem Akademji Umiejętności, Kraków.

RozPORZĄDZENIE MinISTRa ŚRODOwISKa z dnia 9 lipca 2004 r. w sprawie gatunków dziko występujących roślin objętych ochroną. Dz. U. z 2004 r. Nr 168, poz. 1764.

RozPORZĄDZENIE MinISTRA ŚRODOWISKa z dnia 9 października 2014 r. w sprawie ochrony gatunkowej roślin. Dz. U. z 2014 r., poz. 1409.

Sermet E. \& Rolka G. 2013. Pogórniczy spadek na Zrębie Zakrzówka. - W: P. P. ZagożDżon \& M. MadZian (red.), Dzieje górnictwa - element europejskiego dziedzictwa kultury 5, s. 329-338. Oficyna Wydawnicza Politechniki Wrocławskiej, Wrocław.

Skiba S., DrewniK M., SZYMańSKI W. \& ŻYŁa M. 2008. Mapa gleb miasta Krakowa. Uniwersytet Jagielloński, Instytut Geografii i Gospodarki Przestrzennej, Zakład Gleboznawstwa i Geografii Gleb, Kraków. planowanie.um.krakow.pl/bppzoom/index.php?ID-95

Szafer W., Kulczyński S. \& Pawłowski B. 1986. Rośliny polskie. Część I. s. xxxi + 464. Wyd. 5. Państwowe Wydawnictwo Naukowe, Warszawa.

Tląka D. \& Rostański A. 2012. Paprotniki Polski. s. 128. Wydawnictwo „Kubajak”, Krzeszowice. 
UchwaŁA nr CIX/2894/18 Rady Miasta Krakowa z dnia 12 września 2018 r. w sprawie uchwalenia miejscowego planu zagospodarowania przestrzennego „Dla wybranych obszarów przyrodniczych miasta Krakowa" - etap A. Dziennik Urzędowy Województwa Małopolskiego z 2018 r., poz. 6561.

Winther J. L. \& Friedman W. E. 2007. Arbuscular mycorrhizal symbionts in Botrychium (Ophioglossaceae). - American Journal of Botany 94(7): 1248-1255.

WóJCIAK H. 2007. Porosty, mszaki, paprotniki. s. 368. MULTICO Oficyna Wydawnicza, Warszawa.

ZAJĄC M. \& ZAJĄC A. (red.) 1998. Atlas rozmieszczenia roślin naczyniowych w woj. krakowskim. Gatunki prawnie chronione, ginące, narażone i rzadkie. s. 134. Nakładem Pracowni Chorologii Komputerowej Instytutu Botaniki Uniwersytetu Jagiellońskiego, Kraków.

ZAJĄC M. \& ZAJĄC A. 2009. Elementy geograficzne rodzimej flory Polski. s. 94. Nakładem Pracowni Chorologii Komputerowej Instytutu Botaniki Uniwersytetu Jagiellońskiego, Kraków.

Zając M., Zając A. \& Zemanek B. (red.) 2006. Flora Cracoviensis Secunda (Atlas). s. xii + 291. Pracownia Chorologii Komputerowej Instytutu Botaniki Uniwersytetu Jagiellońskiego, Kraków.

ZAPAŁOWICZ H. 1906. Krytyczny przegląd roślinności Galicyi 1. s. 296. Nakładem Akademii Umiejętności, Kraków.

ZARZYCKI K. \& Szeląg Z. 2006. Czerwona lista roślin naczyniowych w Polsce. - W: Z. MireK, K. ZarZYCKI, W. Wojewoda \& Z. Szeląg (red.), Czerwona lista roślin i grzybów Polski, s. 9-20. W. Szafer Institute of Botany, Polish Academy of Sciences, Kraków.

Zarzycki K., Trzcińska-Tacik H., Różański W., Szeląg Z., WoŁeK J. \& KorZeniak U. 2002. Ecological indicator values of vascular plants of Poland. - W: Z. MiREK (red.), Biodiversity of Poland 2, s. 183. W. Szafer Institute of Botany, Polish Academy of Sciences, Kraków.

ŻMUdA A. J. 1920. Rzadsze lub nowe rośliny flory krakowskiej. - Sprawozdanie Komisji Fizjograficznej 53-54: 30-76.

MAgdalena ZARZYKA-RyszKa (autor korespondencyjny), Instytut Botaniki im. W. Szafera Polskiej Akademii Nauk, ul. Lubicz 46, 31-512 Kraków, Polska, e-mail: m.zarzyka@botany.pl

PrZEMYSŁAW RyszKA, Uniwersytet Jagielloński, Instytut Nauk o Środowisku, ul. Gronostajowa 7, 30-387 Kraków, Polska, e-mail: przemyslaw.ryszka@uj.edu.pl

Wptynęto: 19.01.2020 r.; przyjęto do druku: 18.09.2020 r.

DOI: https://doi.org/10.35535/ffgp-2020-0039

\title{
Nowe stanowisko Polystichum aculeatum (Dryopteridaceae) w projektowanym rezerwacie przyrody ,Czarcia Kępa” na Pojezierzu Litewskim
}

\author{
Polystichum aculeatum (L.) Roth (paprotnik kolczysty) jest byliną spotykaną przede \\ wszystkim w Karpatach, Sudetach i na wyżynach południowej Polski (ZAJĄC \& ZAJAc \\ 2001), wyróżniającą dla górsko-podgórskich lasów zboczowych ze związku Tilio pla- \\ typhyllis-Acerion pseudoplatani (MATUsZKIEWICZ 2001), w Polsce objętą ścisłą ochroną \\ gatunkową (RozPORZĄDZENIE 2014).
}

